\title{
EFFECT OF HYDRATION ON POLYTYPISM AND DISORDER IN THE SULFATE-INTERCALATED LAYERED DOUBLE HYDROXIDES OF Li and Al
}

\author{
Latha Pachayappan ${ }^{1}$ and P. Vishnu Kamath $^{1} *$ \\ ${ }^{1}$ Department of Chemistry, Central College, Bangalore University, Bangalore 560 001, India
}

\begin{abstract}
The double hydroxide of $\mathrm{Li}^{+}$and $\mathrm{Al}^{3+}$ is an anionic clay comprising positively charged metal hydroxide layers and intercalated anions. While the structure of the iono-covalently bonded metal hydroxide layer is well known, relatively less knowledge is available regarding the manner in which the anions and water molecules are packed in the interlayer region. The sulfate ion is of special interest as it can potentially intercalate in a multiplicity of orientations and grow an extended hydration sphere. The sulfate-intercalated double hydroxide was synthesized by the imbibition of $\mathrm{Li}_{2} \mathrm{SO}_{4}$ into both the gibbsite and bayerite forms of $\mathrm{Al}(\mathrm{OH})_{3}$ to obtain layered double hydroxides with the nominal formula $\mathrm{Li}_{2} \mathrm{Al}_{4}(\mathrm{OH})_{12} \mathrm{SO}_{4} \cdot \mathrm{nH}_{2} \mathrm{O}(n=4-8)$. The as-prepared compounds were poorly ordered and did not yield any structural information. Temperatureinduced partial dehydration yielded ordered phases of different structures in the two systems. Simulation of the powder patterns of different model structures, followed by structure refinement in both direct and reciprocal spaces, showed that the gibbsite-derived phase yielded a two-layer polytype of hexagonal symmetry (space group $P 6_{3} / \mathrm{m}$ ). The local symmetry of the sulfate ion was close to $D_{2 d}$ with one of the $C_{2}$ axes of the $\mathrm{SO}_{4}{ }^{2-}$ being nearly parallel to the $c$ axis of the crystal. The bayerite-derived phase yielded a one-layer polytype of monoclinic symmetry (space group $C 2 /$ $m$ ). The sulfate ion was oriented with its $C_{3}$ axes tilted away from the stacking direction. Cooling and rehydration (relative humidity $\sim 70 \%$ ) resulted in a reversible expansion of the basal spacing due to the ingress of water molecules from the ambient humidity into the interlayer region. Hydration in both cases resulted in turbostratic disorder. The disorder in the bayerite-derived phase was a result of random intergrowth of motifs with rhombohedral and monoclinic symmetries.
\end{abstract}

Keywords - Layered Double Hydroxide $\cdot$ Rietveld Method $\cdot$ Sulfate $\cdot$ XRPD

\section{INTRODUCTION}

Several industries such as paper and pulp manufacturing units, petroleum refineries, and mining produce acidic wastewater rich in sulfate content. The wastewater generated by such activities seeps through open-pit walls leading to contamination of groundwater. Although sulfate is a non-toxic ion, when present in high concentrations, it corrodes the water transport system (Moosa et al. 2005). Large sulfate concentrations in drinking water result in a noticeable taste and can lead to illness like diarrhea (Fawell et al. 2004). Removal of sulfate ions from industrial wastewater is essential for recycling water in industry. The anaerobic treatment of sulfate-rich wastewater involves reduction of sulfate to $\mathrm{H}_{2} \mathrm{~S}$ by sulfate reducing bacteria (SRB) (Pol et al. 1998). $\mathrm{H}_{2} \mathrm{~S}$ is a toxic gas making sulfate removal an acute industrial problem.

An alternative approach to sulfate removal is sorption using a sorbent with a large surface area, anion exchange capacity, and thermodynamic stability. Layered double hydroxides (LDHs) are proven materials for their capacity to sorb as well as to intercalate inorganic and organic anions. LDHs have been used for the removal of toxic anionic species such as $\mathrm{CrO}_{4}{ }^{2-}$, $\mathrm{AsO}_{3}{ }^{3-} / \mathrm{AsO}_{4}{ }^{3-}$, and $\mathrm{SeO}_{3}{ }^{2-}$ (Rhee et al. 1997; You et al. 2001; Yang et al. 2005; Prasanna et al. 2006; Prasanna and Kamath 2008). The LDHs belong to two different families: II-III LDHs and I-III LDH based on the charge of the cations. The better known II-III LDHs derived from the mineral brucite, $\mathrm{Mg}(\mathrm{OH})_{2}$, consist of positively charged metal hydroxide layers having the composition $\left[M_{x}(\mathrm{II}) M^{\prime}{ }_{1-x}(\mathrm{III})(\mathrm{OH})_{2}\right]^{x+}$ with anions

* E-mail address of corresponding author: vishnukamath8@ hotmail.com

DOI: $10.1007 / \mathrm{s} 42860-019-00011-6$ and water molecules $\left[\left(A^{n-}\right)_{x / n} \cdot y \mathrm{H}_{2} \mathrm{O}\right]$ intercalated in the interlayer region (Cavani et al. 1991). The I-III LDH is derived from $\mathrm{Al}(\mathrm{OH})_{3} \cdot \mathrm{Al}(\mathrm{OH})_{3}$ is composed of charge-neutral layers with the composition $\left[\mathrm{Al}_{2 / 3} \square_{1 / 3}(\mathrm{OH})_{2}\right]$ ( $\square$ : cation vacancy). Imbibition of $\mathrm{Li}+$ ions into the cation vacancies of the $\mathrm{Al}(\mathrm{OH})_{3}$ layers results in positively charged layers of composition $\left[\mathrm{Al}_{2 / 3} \mathrm{Li}_{1 / 3}^{3}(\mathrm{OH})_{2}\right]_{1 / 3+}$. Anions and water molecules $\left.\left[\left(A^{n}\right)\right)_{1 / 3 n} y \mathrm{H}_{2} \mathrm{O}\right]$ are intercalated in the interlayer region for charge neutrality and stability (Serna et al. 1982). The LDH containing $\mathrm{Li}$ and $\mathrm{Al}$ is the only system reported in this family and is abbreviated herein as [Li-Al-X] $\left(\mathrm{X}=\mathrm{NO}_{3}^{-}\right.$, $\mathrm{CO}_{3}{ }^{2-}, \mathrm{Cl}^{-}$, or $\left.\mathrm{Br}^{-}\right)$. The $[\mathrm{Li}-\mathrm{Al}-\mathrm{X}] \mathrm{LDHs}$ are unique in exhibiting shape selective anion intercalation (Fogg et al. 1999). Structure refinement of LDHs containing different anions is a first step towards understanding the mechanism of sorption reactions employed for environmental amelioration.

A survey of the reported structures of [Li-Al] LDHs indicates that they all contain the same iono-covalently bonded metal hydroxide layer (layer group $p \overline{3} 12 / m$ ) (Britto and Kamath 2011). The reported structures differ from one another in (i) the manner in which the metal hydroxide layers are stacked, and/or (ii) the packing of atoms in the interlayer region. The stacking of the metal hydroxide layers could be orthogonal, leading to polytypes of hexagonal and rhombohedral symmetries (Fogg et al. 2002). The stacking of metal hydroxide layers could be non-orthogonal leading to polytypes of monoclinic symmetry (Britto and Kamath 2009). The intercalated $\mathrm{Cl}^{-}$ions exhibit positional disorder in the interlayer region (Besserguenev et al. 1997). The position of the $\mathrm{Br}^{-}$ion depends on the degree of hydration, and is influenced by the ambient relative humidity (Nagendran and Kamath 2013). Intercalated $\mathrm{OH}^{-}$ions induce disorder in the stacking of the metal hydroxide layers (Thiel et al. 1993). Stacking disorders arise due to the random intergrowth of different polytypes (Britto and Kamath 
2012), and manifest themselves in the broadening of reflections arising from select crystal planes (Britto et al. 2008). The packing of polyatomic oxoanions is further complicated by changes in the orientation of the anions at different degrees of hydration. The intercalated $\mathrm{NO}_{3}{ }^{-}$ion not only changes its orientation but also generates an incommensurate phase upon hydration (Nagendran et al. 2016, 2018).

Intercalation of the sulfate ion in [Li-Al] LDH is interesting for many reasons:

(1) The sulfate ion has a large hydration enthalpy (Smith 1977) and has the capacity to extend its hydration in the interlayer region to a higher degree than the nitrate ion.

(2) The free $\mathrm{SO}_{4}{ }^{2-}$ ion is of $T_{d}$ symmetry, and can potentially intercalate with any one of its axes of rotation $-C_{4}, C_{3}$, or $C_{2}$ - parallel to the stacking direction.

The main objective of this work was to obtain structure models that best describe the packing of sulfate ions and intercalated water molecules in the interlayer region of [Li-Al] LDHs. One of the cardinal features of clay-like materials is their ability to swell by taking in water molecules from their surroundings. A secondary objective was to investigate if [Li-Al-SO $\mathrm{SO}_{4} \mathrm{LDH}$ exhibits a reversible expansion of the interlayer region as a function of the ambient relative humidity, and thereby establish the crystal chemistry underlying the swelling phenomenon.

\section{EXPERIMENTAL SECTION}

Bayerite- $\mathrm{Al}(\mathrm{OH})_{3}\left(60.2 \% \mathrm{Al}_{2} \mathrm{O}_{3}\right.$ content) was synthesized as described elsewhere by precipitation by the addition of $\mathrm{NH}_{3}$ to $\mathrm{AlCl}_{3}$ (Merck Life Science Pvt. Ltd., Mumbai, India) solution (Poeppelmeier and Hwu 1987). Gibbsite-Al(OH) $)_{3}(64.1 \%$ $\mathrm{Al}_{2} \mathrm{O}_{3}$ content) was provided by the Jawaharlal Nehru Aluminium Research Development and Design Centre (Nagpur, India). The [Li-Al-SO $\mathrm{S}_{4}$ LDHs were prepared by suspending $\sim 0.5 \mathrm{~g}$ of bayerite or gibbsite in a Teflon-lined autoclave containing $\sim 2 \mathrm{M} \mathrm{Li}_{2} \mathrm{SO}_{4}(10 \mathrm{~mL})$ solution ( $>99 \%$, SISCO Research Laboratories Pvt. Ltd., Mumbai, India) followed by hydrothermal treatment at $180^{\circ} \mathrm{C}$ for $24 \mathrm{~h}$. The resulting precipitate was thereafter centrifuged, washed 3-4 times with Type II water (specific resistance $15 \mathrm{M} \Omega \mathrm{cm}$, Millipore Academic water purification system, Molsheim, France), and dried in an air oven at $65^{\circ} \mathrm{C}$. The samples were stored in air-tight screw cap bottles without desiccation.

The $\mathrm{Li}^{+}$contents were estimated by flame photometry (Elico, Hyderabad, India), $\mathrm{SO}_{4}{ }^{2-}$ contents by ion chromatography (Metrohm Model 861 Advanced Compact Ion Chromatograph fitted with a Metrosep SUP 5150 column, Herisau, Switzerland), $\mathrm{Al}^{3+}$ contents by gravimetry, and intercalated $\mathrm{H}_{2} \mathrm{O}$ contents by thermogravimetry (Mettler Toledo, TG/SDTA Model $851^{\mathrm{e}}$ system, Schwerzenbach, Switzerland; $30-900^{\circ} \mathrm{C}$, heating rate $5^{\circ} \mathrm{C} / \mathrm{min}$, flowing air) in g-[Li-Al-SO $\left.{ }_{4}\right]$ and b-[Li-Al-SO 4$]$ LDHs (g: gibbsite-derived; b: bayerite-derived).

A Bruker D8 Advance diffractometer (Karlsruhe, Germany) ( $\mathrm{Cu} \mathrm{K} \alpha$ radiation, $\lambda=1.5418 \AA$ ) operating in reflection geometry mode was used to characterize the samples. In situ X-ray powder diffraction (XRPD) measurements at different temperatures $\left(30-120^{\circ} \mathrm{C}\right)$ and relative humidity $(\mathrm{RH})$ values $(60-90 \%)$ were performed using an Anton Paar CHC plus humidity chamber (Graz, Austria) as an attachment. The XRPD patterns were recorded over the $5-100^{\circ} 2 \theta$ range with a step size of $0.02^{\circ} 2 \theta$ (counting time $10 \mathrm{~s} \mathrm{step}^{-1}$ ). The XRPD patterns were indexed, and the lattice parameters refined using the APPLEMAN code built into the PROSZKI suite (Easocha and Lewinski 1994). The DIFFaX code (Treacy et al. 1991, 2005) was used to simulate the XRPD patterns to identify the relationship between the successive layers in the LDH. Within the DIFFaX formalism, a single metal hydroxide layer extracted from the published structure of g-[Li-Al-Cl] LDH was identified as a structural synthon, and used for all the simulations. All the symmetry-related atoms corresponding to the metal hydroxide layer within the unit mesh were explicitly used as input. The metal hydroxide layers were stacked one above another by using different stacking vectors. The Laue symmetry was declared UNKNOWN to enable code DIFFaX to compute the Laue symmetry. The DIFFaX code computes the diffraction intensity for an infinite stacking by integrating the intensity emerging from each layer. A Lorentzian profile function with $\mathrm{FWHM}=0.2^{\circ} 2 \theta$ was used to broaden the Bragg reflections in the simulated XRPD patterns. The XRPD patterns simulated using different stacking vectors were compared with the experimental XRPD patterns to identify the corresponding polytypes. Once the polytype was identified, the structure and orientation of metal hydroxide layers were used as a partial structure model for refinement. The position and orientation of the intercalated sulfate ions was determined using code FOX (Favre-Nicolin and Černý 2002) in the absence of prior knowledge of the interlayer structure. The $\mathrm{SO}_{4}{ }^{2-}$ ions and water molecules were inserted into the interlayer region and allowed to translate and rotate randomly. After each step, the XRPD pattern was computed and compared with the observed pattern. A Monte Carlo approach was employed for structure optimization using $R_{\text {wp }}$ (wp: weighted profile) and $R_{\mathrm{p}}$ (p: profile) (Larson and Von Dreele 2004) as the cost functions. This process amounts to structure optimization in direct space and yields an approximate structure model. The model was exported to the GSAS code (Soediono 1989) to complete the structure refinement in reciprocal space in the conventional manner.

\section{RESULTS AND DISCUSSION}

Two polymorphic modifications of $\mathrm{Al}(\mathrm{OH})_{3}$, namely bayerite (Rothbauer et al. 1967) and gibbsite (Megaw 1934), are well known, and are used as precursors for the synthesis of I-III LDHs. Both gibbsite and bayerite crystallize in monoclinic symmetry and contain the same metal hydroxide layer, 
which is designated by the symbol $P$. Bayerite is obtained by stacking the layers in the sequence $\cdots P P P \cdots$. Gibbsite is obtained by the stacking sequence $\cdots P \bar{P} P \cdots$, where $\bar{P}$ is the mirror image of $P$. Consequently, gibbsite is a two-layer polytype (space group $P 12_{1} / n 1, a=8.676 \AA, b=5.070 \AA, c=9.721 \AA, \beta=94.57^{\circ}$ ) (Saalfeld and Wedde 1974) and bayerite is a one-layer polytype $\left(P 12_{1} / a 1, a=5.062 \AA, b=8.671 \AA, c=4.713 \AA, \beta=90.27^{\circ}\right)$ (Rothbauer et al. 1967) (see Supporting Information [SI, Fig. S1], Supplemental Materials Section, deposited with the Editor in Chief and available (Supplementary material)).

Gibbsite-derived g-[Li-Al- $X]$ LDHs $\left(X=\mathrm{Cl}, \mathrm{Br}\right.$, and $\left.\mathrm{NO}_{3}\right)$ have been studied widely and shown to crystallize as two-layer polytypes. Bayerite-derived b-[Li-Al- $X]$ LDHs $(X=\mathrm{Cl}, \mathrm{Br})$ are less well known and are shown to crystallize as one-layer polytypes.

\section{Compositional analysis}

Hydrothermal treatment of both gibbsite and bayerite in a concentrated aqueous solution of $\mathrm{Li}_{2} \mathrm{SO}_{4}$ yielded white powder samples, which were readily soluble in mineral acids. Flame photometry analysis of an acid solution of both samples showed the presence of $\mathrm{Li}^{+}$ (Table 1), indicating the success of the imbibition reaction. $\mathrm{SO}_{4}{ }^{2-}$ content estimated independently by ion chromatography matched stoichiometrically the $\mathrm{Li}^{+}$ion content in the b-[Li-Al-SO $\left.{ }_{4}\right]$ LDHs (observed $\left[\mathrm{Li}^{+}\right] /\left[\mathrm{SO}_{4}{ }^{2}\right.$ $\left.{ }^{-}\right]=1.96$, ideal value $=2$ ). The $\mathrm{Al}^{3+}$ content obtained gravimetrically yielded a ratio of $\left[\mathrm{Li}^{+}\right] /\left[\mathrm{Al}^{3+}\right]=0.47$ (ideal value $=0.5$ ). The TGA plot (Fig. 1) showed three distinct mass-loss steps with inflections at $120^{\circ} \mathrm{C}$ (step I), $250^{\circ} \mathrm{C}$ (step II), and $340^{\circ} \mathrm{C}$ (step III). The mass of the residue obtained at $800^{\circ} \mathrm{C}$ was $\sim 55.7 \%$. As the sulfate ion does not volatilize at this temperature in air, the residue comprised $\mathrm{Li}_{2} \mathrm{SO}_{4}+2 \mathrm{Al}_{2} \mathrm{O}_{3}$. The mass observed at $250^{\circ} \mathrm{C}$ (75.3\%) corresponds to dehydrated LDH having the formula $\left[\mathrm{Li}_{2} \mathrm{Al}_{4}(\mathrm{OH})_{12}\right]\left(\mathrm{SO}_{4}\right)$, suggesting that step III was due to dehydroxylation. The mass-loss observed in the temperature range $30-250^{\circ} \mathrm{C}(\sim 25 \%)$ was due to loss of adsorbed water (step I, $14 \%, 30-120^{\circ} \mathrm{C}$ ) and intercalated water (step II, $11 \%, 120-250^{\circ} \mathrm{C}$ ), respectively. A

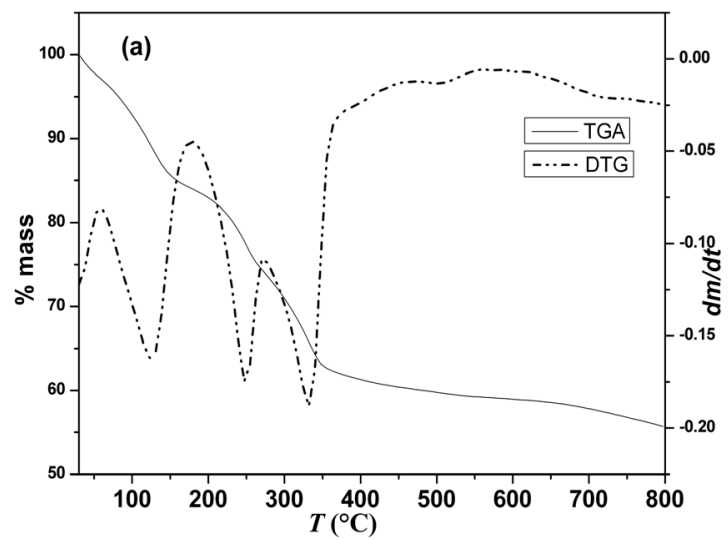

combination of these results yielded an empirical formula for LDH (Table 1) which could be approximated as $\left[\mathrm{Li}_{2} \mathrm{Al}_{4}(\mathrm{OH})_{12}\right] \mathrm{SO}_{4} \cdot 4.44 \mathrm{H}_{2} \mathrm{O}$.

A similar approach to arrive at the composition of the $\mathrm{g}-[\mathrm{Li}-$ $\left.\mathrm{Al}-\mathrm{SO}_{4}\right] \mathrm{LDH}$ suffered certain limitations primarily due to the presence of small quantities of unreacted gibbsite. The $\mathrm{Al}^{3+}$ content was overestimated. The $\mathrm{SO}_{4}{ }^{2-}$ content was, therefore, taken as the lead indicator of the $\mathrm{LDH}$ composition and $\mathrm{Al}^{3+}$ observed in excess over the stoichiometric requirement $\left(\left[\mathrm{Al}^{3+}\right] /\left[\mathrm{SO}_{4}{ }^{2-}\right]=4\right)$ was assigned to the unreacted $\mathrm{Al}(\mathrm{OH})_{3}$. A combination of independent analyses yielded a ratio $\left[\mathrm{Li}^{+}\right] /$ $\left[\mathrm{SO}_{4}{ }^{2-}\right]=1.76$ (ideal value $=2$ ) and $\left[\mathrm{Li}^{+}\right] /\left[\mathrm{Al}^{3+}\right]=0.44$ (ideal value $=0.5)($ Table 1$)$. The TGA curve $($ Fig. 1$)$ showed a threestep mass-loss over the temperature range $30-900^{\circ} \mathrm{C}$. The mass of the residue obtained was $55.2 \%$ and was due to $\mathrm{Li}_{2} \mathrm{SO}_{4}+2.13 \mathrm{Al}_{2} \mathrm{O}_{3}$. Assigning the three steps to loss of adsorbed water (14.8\%), intercalated water (10.3\%), and dehydroxylation $(19.1 \%)$ yielded an empirical formula $\left[\mathrm{Li}_{0.44} \mathrm{Al}(\mathrm{OH})_{3}\right]\left[\mathrm{SO}_{4}\right]_{0.25} \cdot 1.23 \mathrm{H}_{2} \mathrm{O}$ (Table 1). Structure refinement was carried out using the ideal value $\left[\mathrm{Li}^{+}\right] /\left[\mathrm{Al}^{3+}\right]=0.5$ for the purpose of electroneutrality. The departure of the observed composition from the ideal composition was deemed to be negligible from a powder diffraction point of view.

\section{Structure of the g-[Li-Al-SO $\left.\mathrm{S}_{4}\right] \mathrm{LDH}$}

The as-prepared LDH (denoted G-I) yielded an XRPD pattern (Fig. S2) with two intense reflections in the lowangle region at $10^{\circ} 2 \theta(8.84 \AA)$ and $20^{\circ} 2 \theta(4.44 \AA)$, respectively, followed by numerous weak and broad undulations in the $25-55^{\circ} 2 \theta$ region. These features are typical of layered solids with turbostratic disorder. In such crystals, periodicity is observed only along the stacking direction leading to intense and sharp basal reflections. A close look at the first basal reflection (inset in Fig. S2) showed a distinct asymmetry on the high-angle side, along with a split in the second basal reflection, showing that the asprepared sample comprised LDH motifs with different basal spacings. Basal spacing differences arise due to differences in the degree of hydration. Such materials are prone to undergo temperature- and humidity-driven transitions that result in pure polytypes.

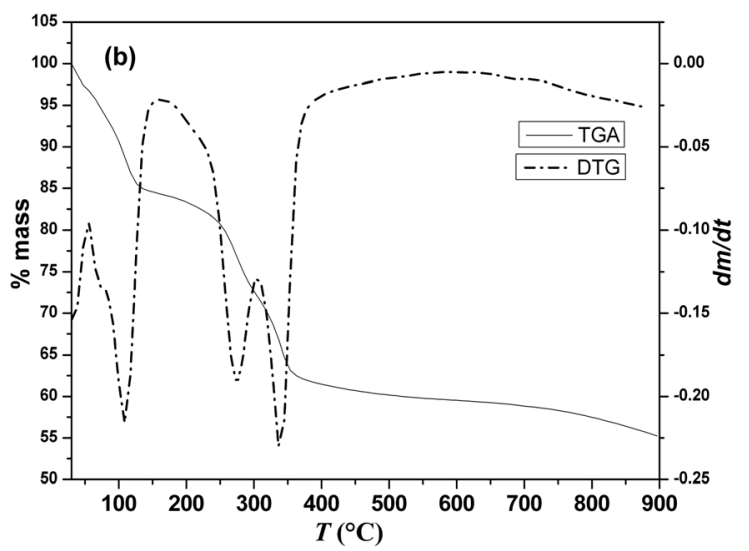

Fig. 1 TGA (continuous line) and DTG (dashed line) data of the as-prepared (a) b-[Li-Al-SO 4 , and (b) g-[Li-Al-SO LDHs $_{4}$ 
Table 1 Results of compositional analysis

\begin{tabular}{llllll}
\hline Sample & $\mathrm{Li}^{+}(\mathrm{wt} \%)$ & $\mathrm{Al}^{3+}(\mathrm{wt} \%)$ & $\mathrm{SO}_{4}{ }^{2-}(\mathrm{wt} \%)$ & $\begin{array}{l}\text { Mass loss } \\
\text { from TGA (\%) }\end{array}$ & Approximate composition of sample. \\
\hline$\left[\mathrm{Li}-\mathrm{Al}-\mathrm{SO}_{4}\right]$ (gibbsite-based) & $2.52(2.31)$ & $23.70(21.85)$ & $19.80(18.18)$ & 44.8 & $\begin{array}{r}\left.\mathrm{Li}_{0.44 \pm 0.01} \mathrm{Al}(\mathrm{OH})_{3}\right]\left[\mathrm{SO}_{4}\right]_{0.25 \pm 0.005} \cdot 1.2 \\
\mathrm{H}_{2} \mathrm{O}+0.07\left[\mathrm{Al}(\mathrm{OH})_{3}\right]^{*}\end{array}$ \\
{$\left[\mathrm{Li}-\mathrm{Al}_{\left.-\mathrm{SO}_{4}\right] \text { (bayerite-based) }}\right.$} & $2.94(2.63)$ & $23.98(21.73)$ & $20.44(18.57)$ & 44.3 & {$\left[\mathrm{Li}_{0.47 \pm 0.01} \mathrm{Al}(\mathrm{OH})_{3}\right]\left[\mathrm{SO}_{4}\right]_{0.24 \pm 0.005} \cdot 1.1 \mathrm{H}_{2} \mathrm{O}$} \\
\hline
\end{tabular}

*Unreacted $\mathrm{Al}(\mathrm{OH})_{3}$ observed in the experimental pattern of G-II and G-III

Values in the parenthesis were calculated from the approximate composition

G-I was heated to different temperatures and at $100^{\circ} \mathrm{C}$ corresponding to the first inflection point in the TGA curve (Fig. 1), a phase G-II with an XRPD pattern comprising sharp and well defined peaks (Fig. S3a) was obtained. The pattern could be indexed to a two-layer cell (polytype $2 H$ ) with $a=$ $b=5.0944 \AA, c=17.1592 \AA$ (Table S1). Numerous structure models are available for the $2 H$ polytype in which the metal hydroxide layers follow the $\cdots P \bar{P} P \cdots$ stacking sequence, typical of the gibbsite precursor. A DIFFaX simulation (Fig. S3b) of the XRPD pattern using the metal hydroxide layers obtained from the structure of the g-[Li-Al-Cl] LDH reported earlier (Nagendran and Kamath 2013) generated all the observed reflections confirming the $P \cdots \bar{P}$ interlayer relationship. The $P \cdots \bar{P}$ interlayer relationship generates the space group $P 6_{3} / m$ in this LDH system. In the absence of a precedent for the structure of the interlayer sulfate in this family of LDHs, metal hydroxide layers were used as a partial structure model, and $\mathrm{FOX}$ code was employed to determine the possible positions of the $\mathrm{SO}_{4}{ }^{2-}$ ions and water molecules in the interlayer region. To this end, the $\mathrm{SO}_{4}{ }^{2-}$ ion was introduced as a molecule along with an oxygen atom (Ow1, for intercalated water) into the interlayer. The two species were allowed to translate randomly. The $\mathrm{SO}_{4}{ }^{2-}$ ion was also randomly rotated. During the optimization process, the structure was periodically visualized for any unrealistic variations in the bond length and bond angle values. When the $\mathrm{S}$ atom of the $\mathrm{SO}_{4}{ }^{2-}$ was confined to a plane midway between the metal hydroxide layers, a stable structure optimization was obtained $\left(R_{\mathrm{wp}}=0.173 ; R_{\mathrm{p}}=0.106\right)$.

To complete the structure refinement in the reciprocal lattice, the structure model obtained from code $F O X$ was exported into code GSAS. The non-structural parameters were refined initially. Difference Fourier maps were generated to find the positions of additional intercalated water molecules. Successive difference Fourier maps indicated the presence of water molecules at $4 e(0,0,0.1767)(\mathrm{Ow} 2)$, and $2 a(0,0,0.25)$ (Ow3) sites. These sites are proximal to the $\mathrm{Li}^{+}$ion $2 b(0,0,0)$ showing a strong interaction of the intercalated water molecules with the $\mathrm{Li}^{+}$ion in the metal hydroxide layer. The cumulative occupancy of Ow1, Ow2, and Ow3 atoms was found to be $12 \%$ lower than the water content expected from the TGA at $100^{\circ} \mathrm{C}$. At this stage, the electron density reflected in the difference Fourier plots was fully accounted for. To improve the fit under the second basal reflection, an orientation parameter was introduced along [002] to complete the fit (Fig. 2, Table 2). Water molecule Ow1 occupies a general site $12 i(x, y, z)$, while Ow2 and Ow3 obtained in the later stages of refinement occupy special positions (Table S2), thus infusing confidence in the refinement process.

The $\mathrm{S}$ atom of the intercalated $\mathrm{SO}_{4}{ }^{2-}$ ion occupies a special position of high degeneracy ( $6 h)$ proximal to the $\mathrm{Al}^{3+}$ ion. The $\mathrm{SO}_{4}{ }^{2-}$ ion is oriented with its two-fold axis parallel to the

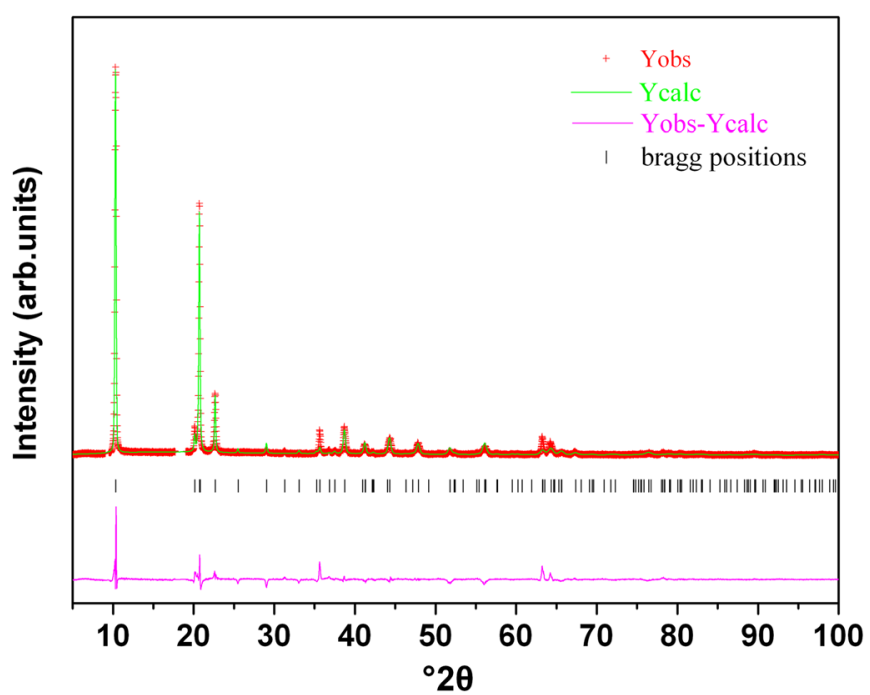

Fig. 2 Rietveld fit of the in situ XRPD pattern of g-[Li-Al-SO $\mathrm{SO}_{4}\left(T=100^{\circ} \mathrm{C}\right)$. The excluded region corresponds to the reflection of unreacted gibbsite 
Table 2 Results of rietveld refinement of the structures of [ $\left.\mathrm{Li}-\mathrm{Al}-\mathrm{SO}_{4}\right] \mathrm{LDHs}$

\begin{tabular}{lll}
\hline & Phase G-II $\left(T=100{ }^{\circ} \mathrm{C}\right)$ & Phase B-II $\left(T=120{ }^{\circ} \mathrm{C}\right)$ \\
\hline Molecular Formula & {$\left[\mathrm{Li}_{2} \mathrm{Al}_{4}(\mathrm{OH})_{12}\right]\left(\mathrm{SO}_{4}\right) \cdot 3 \mathrm{H}_{2} \mathrm{O}$} & {$\left[\mathrm{Li}_{2} \mathrm{Al}_{4}\left(\mathrm{OH}_{12}\right]\left(\mathrm{SO}_{4}\right) \cdot 3.1 \mathrm{H}_{2} \mathrm{O}\right.$} \\
Crystal Symmetry & Hexagonal & $\mathrm{Monoclinic}$ \\
Space Group & $P 6_{3} / m$ & $C 12 / m 1$ \\
Cell Parameters & & 5.0747 \\
$\quad a(\AA)$ & 5.0898 & 8.8524 \\
$\quad b(\AA)$ & 5.0898 & 8.7723 \\
$\quad c(\AA)$ & 17.1464 & 99.705 \\
$\quad \beta($ deg $)$ & 90 & 388.44 \\
Volume $\left(\AA^{3}\right)$ & 384.68 & 4749 \\
Data Points & 4663 & 19 \\
Parameters Refined & 16 & 0.1491 \\
$R_{\mathrm{wp}}$ & 0.1869 & 0.1145 \\
$R_{\mathrm{p}}$ & 0.1339 & 0.1384 \\
$R_{\left(F^{2}\right.}$ & 0.1714 & 2.951 \\
$\chi^{2}$ & 6.712 & 2 \\
\hline
\end{tabular}

crystallographic $c$ axis (Fig. 3) (CCDC No. 1852882). If the crystallographic $c$ axis is treated as the principal axis, then the symmetry of the sulfate is reduced to $D_{2 d}$ upon intercalation. In this orientation, only two oxygen atoms $(\mathrm{O} 2$ and $\mathrm{O} 3)$ of the sulfate ion hydrogen bond with the metal hydroxide layer at distances that range from 2.39 to $2.94 \AA$ (Table S3). Oxygen atoms (O2 and $\mathrm{O} 5)$ of the $\mathrm{SO}_{4}{ }^{2-}$ ion hydrogen bond strongly with the water molecules with $\mathrm{O}-\mathrm{O}$ bond distances in the range 2.41-2.75 $\AA$. The contact distance between the $\mathrm{O}$ atoms of intercalated water molecules and the hydroxyl $\mathrm{O}$ (O1) of the metal hydroxide layer is in the range 2.82$3.87 \AA$, indicative of a much weaker interaction.

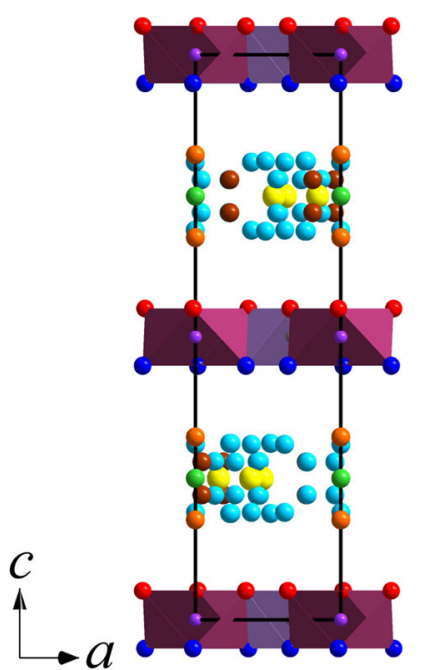

(a)
On cooling and rehydration (Relative Humidity 70\%), G-II transformed into a new phase G-III with a basal spacing of $10.6 \AA$ (Fig. 4). An expansion of the basal spacing by nearly $2 \AA$ is due to the ingress of water molecules from the vapor phase. The increased basal spacing includes an interlayer region of $\sim 91 \AA^{3}$ volume equivalent to $\sim 8.3$ water molecules. Given that structure refinement of G-II yields approximately three water molecules in the immediate vicinity of the $\mathrm{SO}_{4}{ }^{2-}$ ion, the additional five molecules of $\mathrm{H}_{2} \mathrm{O}$ in G-III are in the second coordination sphere of the $\mathrm{SO}_{4}{ }^{2-}$ ion. The presence of such a massive amount of water results in turbostratic disorder, and all $h k l$ reflections are

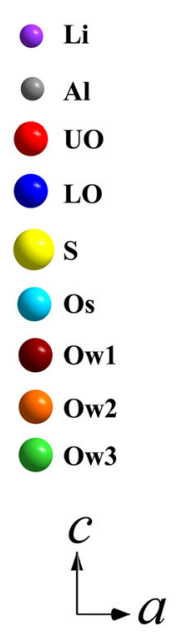

(b)

Fig. 3 (a) Structure of g-[Li-Al-SO 4$]\left(T=100{ }^{\circ} \mathrm{C}\right)$ viewed along the $b$ axis, and (b) the asymmetric unit 


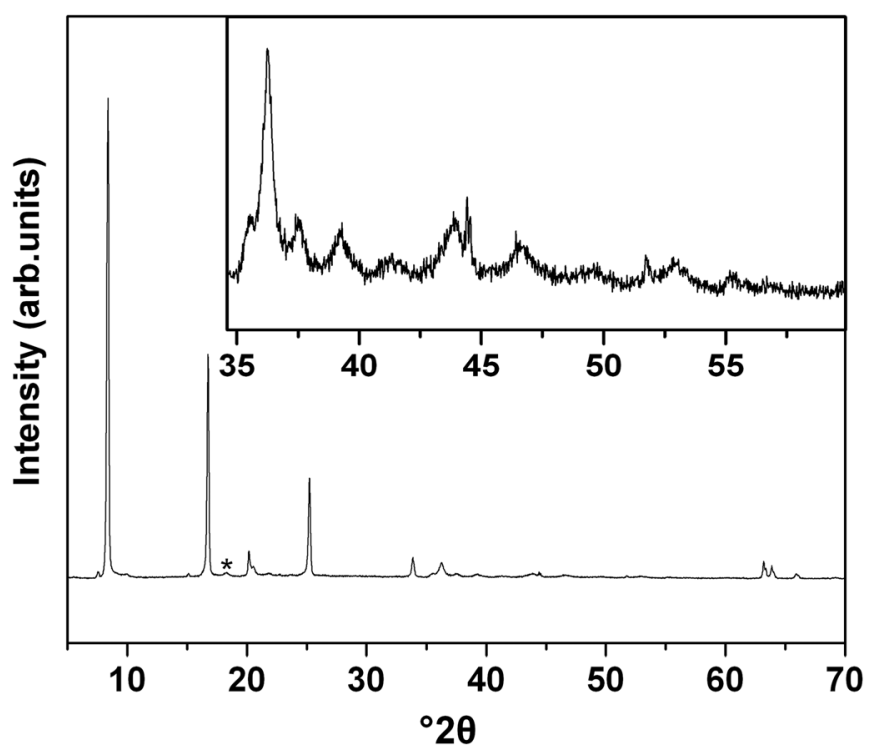

Fig. 4 XRPD pattern of $\mathrm{g}$-[Li-Al-SO $\left.\mathrm{L}_{4}\right]$ obtained in situ at $\mathrm{RH}=70 \%$. The reflection marked by the asterisk is due to the 002 plane of the unreacted gibbsite. Inset shows the saw-tooth line shape of reflections arising due to turbostratic disorder

obliterated. The XRPD pattern is dominated by $00 l(l=1$, $2,3,4)$ reflections. In the absence of any meaningful structural information, it is instructive to examine the results of molecular dynamics (MD) simulation studies (Chen et al. 2018) on a related cation-ordered system. The water molecules are shown to coordinate with both hydroxyl ions and intercalated sulfate ions in a cooperative manner.

In conclusion, the results show that the as-prepared gibbsite-derived LDH exhibits basal-spacing dynamics involving a reversible variation of the basal spacing by nearly $2 \AA$ as a function of the relative humidity. When excess water was removed the LDH adopted the structure of a two-layer hexagonal polytype. On hydration, the ingress of water molecules from the vapor phase introduced turbostratic disorder in the stacking of the metal hydroxide layers.

Structure of the $b$-[Li-Al-SO $\left.\mathrm{L}_{4}\right] \mathrm{LDH}$

The as-prepared LDH derived from bayerite (denoted B-I) yielded an XRPD pattern (Fig. S4a) with basal reflections at $10^{\circ} 2 \theta(8.85 \AA)$ and $20.24^{\circ} 2 \theta(4.39 \AA)$. The first basal reflection

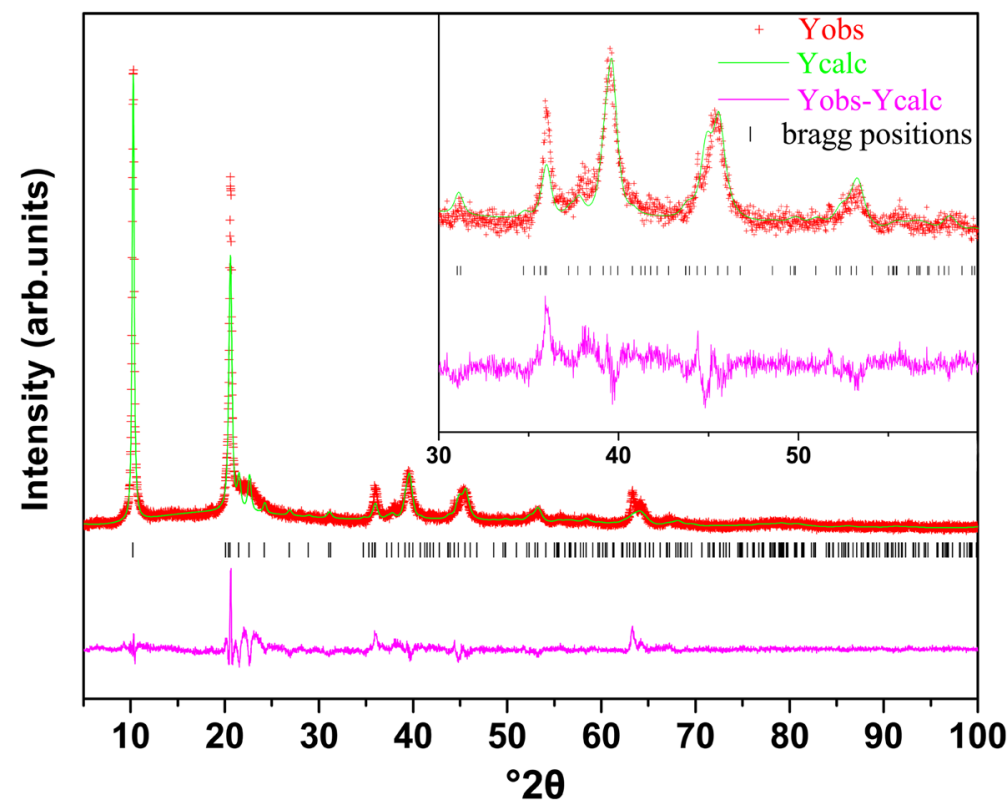

Fig. 5 Rietveld fit of the in situ XRPD pattern of b-[Li-Al-SO 4$]\left(T=120^{\circ} \mathrm{C}\right)$ 


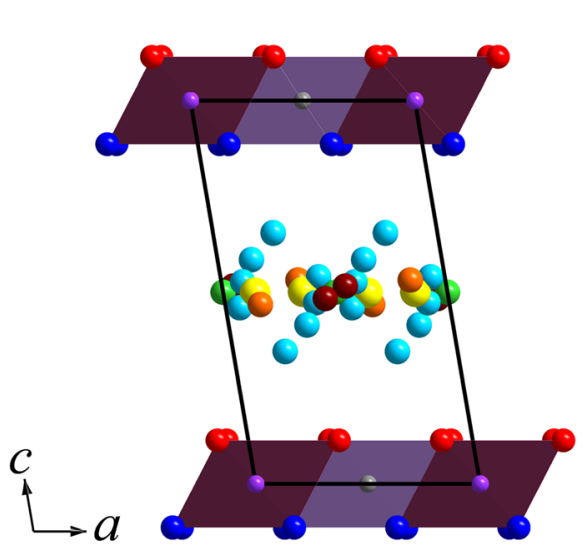

(a)

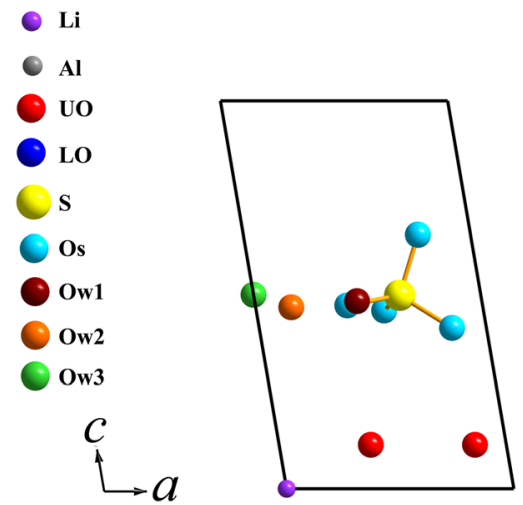

(b)

Fig. 6 (a) Structure of b-[Li-Al-SO $\left.{ }_{4}\right]\left(T=120^{\circ} \mathrm{C}\right)$ viewed along the $b$ axis, and (b) the asymmetric unit

has a shoulder on the low-angle side suggesting the existence of motifs with different degrees of hydration. As a consequence, the reflections in the mid- $2 \theta$ region $\left(25-55^{\circ} 2 \theta\right)$ are broad and few in number, indicating disorder. No structural information could be deduced from this pattern. The sample was investigated for temperature- and humidity-induced structural ordering.

When B-I was heated to $120^{\circ} \mathrm{C}$, i.e. the first inflection point in the TGA curve (Fig. 1), a new phase (B-II) with basal reflections at $10.3^{\circ} 2 \theta(8.59 \AA)$ and $20.6^{\circ} 2 \theta(4.31 \AA)$ was obtained (Fig. $\mathrm{S} 4 \mathrm{~b})$. A broad hump was seen on the higher-angle side of the second basal reflection. When B-II was cooled and rehydrated (RH 70\%), an expansion of the basal spacing by $\sim 2 \AA$ (phase BIII) was observed (Fig. S4c). In the first instance, the layer-tolayer relationship was determined using DIFFaX simulations. The XRPD pattern of B-II could be simulated by stacking the metal hydroxide layer $(P)$ using the stacking vector $(2 / 3,0,1)$ (Fig. S5). This stacking vector also generated three Bragg reflections on the higher-angle side of the second basal reflection, showing that the hump observed in the $22-25^{\circ} 2 \theta$ region is structural in origin. The XRPD pattern of B-II was indexed to a cell of monoclinic symmetry (Table S1, $a=5.0925 \AA$; $b=$ $8.8211 \AA, c=8.7612 \AA, \beta=101.2^{\circ}$ ) corresponding to a onelayer polytype (polytype $1 M$ ). Angle $\beta$ corresponds to the nonorthogonal stacking direction. A satisfactory LeBail fit to the space group $C 2 / m$ could be secured in keeping with suggestions from earlier work (Nagendran and Kamath 2017). The metal hydroxide layer extracted from the structure of $b-[\mathrm{Li}-\mathrm{Al}-\mathrm{Br}] \mathrm{LDH}$ was used as a partial structure model for structure refinement. The positions of the $\mathrm{SO}_{4}{ }^{2-}$ ion and one intercalated water molecule were obtained from the $F O X$ code. The $\mathrm{SO}_{4}{ }^{2-}$ ion was restricted

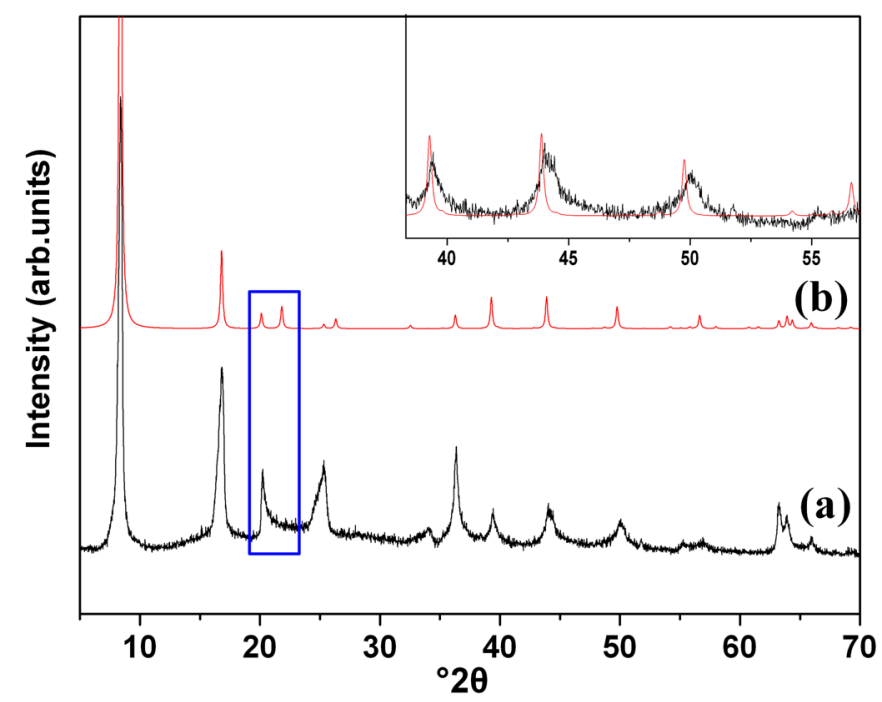

Fig. 7 (a) XRPD pattern of b- $\left[\mathrm{Li}-\mathrm{Al}-\mathrm{SO}_{4}\right]$ obtained in situ $(\mathrm{RH}=70 \%)$ compared to $(\mathbf{b})$ XRPD pattern simulated for $\cdots P P P \cdots$ stacking using $(0,0$, 1) stacking vector. In the inset, the mid- ${ }^{\circ} 2 \theta$ region $\left(38-57^{\circ} 2 \theta\right)$ of the observed and the simulated XRPD pattern is expanded to show the mismatch in the positions of reflections. The rectangular box highlights the asymmetric peak shape in the observed XRPD pattern when compared with that simulated 


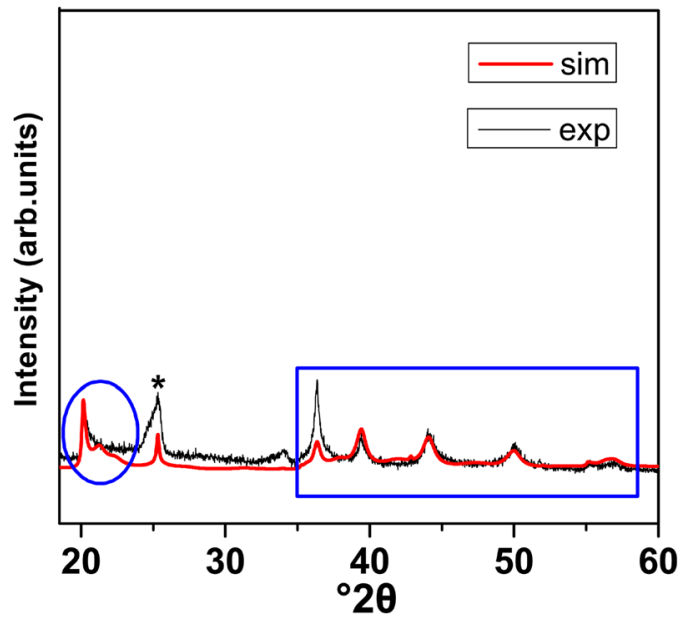

Fig. 8 Simulation of the of the XRPD pattern of b-[Li-Al-SO obtained in situ $(\mathrm{RH}=70 \%)$ by incorporating $30 \%(1 / 7,0, \mathrm{z})+20 \%$ $(6 / 7,0, z)+30 \%[(1 / 7+1 / 3), 2 / 3, z]+20 \%[(6 / 7+1 / 3), 2 / 3, z]$. The black trace corresponds to the observed, and the red trace corresponds to that simulated. The first and the second basal reflections are not shown, and the Bragg reflection marked with asterisk corresponds to the third-order basal reflection. The circle and the rectangular box highlight the good match between observed and simulated XRPD patterns in both the low-angle $\left(5-30^{\circ} 2 \theta\right)$ and the mid- ${ }^{\circ} 2 \theta$ region $\left(38-60^{\circ} 2 \theta\right)$

to a plane mid-way in the interlayer region. The resulting structure model was input into the code GSAS and a series of difference Fourier plots was obtained at different stages of the refinement process. Additional water molecules (Ow2, Ow3) were added at $4 i(0.1567,0,0.4678)$ and $4 h(0,0.231,0.5)$ sites. The position of Ow1 indicated by the FOX code is a general $8 j$ $(0.4506,0.1105,0.4837)$ site. Ow2 and Ow3 determined later were found to occupy special positions (Table S2). The occupancies of the Ow1, Ow2, and Ow3 water molecules were both individually and cumulatively refined. The suggested total water content in the interlayer was $11 \%$ less than that indicated by TGA data. Nevertheless, the final Rietveld fit (Fig. 5, Table 2) is quite satisfactory. The resulting structure (Fig. 6) showed that the $C_{3}$ axis of the intercalated $\mathrm{SO}_{4}{ }^{2-}$ ion is tilted away from the crystallographic $c$ axis (CCDC No. 1852881).

Phase B-III obtained on cooling and rehydration showed an XRPD pattern with the following characteristics (Fig. S4c): (i) three basal reflections were observed, (ii) a saw-tooth shaped reflection appeared at $\sim 20^{\circ} 2 \theta$, and (iii) reflections in the $35-$ $65^{\circ} 2 \theta$ region were considerably broadened. The XRPD pattern simulated using stacking vector $(0,0,1)$ (polytype $1 H$ ) generated all the reflections observed in the $30-60^{\circ} 2 \theta$ region with some mismatch in the intensities and peak shapes between the observed and computed reflections (Fig. 7). The saw-tooth reflection in the observed pattern covered the range of $2 \theta$ values wherein the 100 and 110 reflections appear in the $1 H$ polytype. This kind of asymmetric broadening of the $h k 0$ reflections, also called Warren broadening (Warren and Bodenstein 1966), is attributed to turbostratic disorder. The latter is an extreme model of planar faults, wherein the iono- covalently bonded layers are stacked regularly, but are randomly rotated about the stacking direction. A full profile simulation of the observed pattern could not be secured, but critical portions of the profile spanning $18-24^{\circ} 2 \theta$ and $38-$ $60^{\circ} 2 \theta$ could be simulated (Fig. 8) using a multiplicity of stacking vectors in different proportions: $30 \%(1 / 7,0,1)$; $20 \%(6 / 7,0,1) ; 30 \%[(1 / 7+1 / 3), 2 / 3,1]$, and $20 \%[(6 / 7+1 /$ $3), 2 / 3,1]$. These stacking vectors were selected on the basis of the structural synthon approach, which is more fully described elsewhere (Britto and Kamath 2011). According to this approach, stacking vectors of the type $(1 / \mathrm{n}, 0,1)$ and $(1-1 / \mathrm{n}, 0,1)$ yielded a pair of "enantiomorphic" polytypes of monoclinic symmetry. The stacking vector $(1 / 3,2 / 3,1)$ generated a crystal of rhombohedral symmetry. A vector sum of the two families of stacking vectors yielded a faulted crystal with random intergrowths of rhombohedral and monoclinic motifs. MD simulation studies of hydrated LDHs also predicted intergrowth of rhombohedral and monoclinic polytypes (Chen et al. 2018), and the observations reported here provide experimental evidence for the simulations.

To conclude this section, the b-[Li-Al-SO $\left.\mathrm{SO}_{4}\right] \mathrm{LDH}$ precipitated with the sulfate ions in an incomplete hydration sphere. Long-range order was ill defined. On heating, the crystal ordered itself and adopted the structure of a one-layer polytype having monoclinic symmetry. On hydration, an expansion occurred in the interlayer region. The resultant weakening in the layer-interlayer interaction resulted in a crystal replete with stacking disorders, wherein the local symmetry of the faulted regions was either rhombohedral or monoclinic.

The approach adopted in this study has two limitations.

(1) The water content suggested by structure refinement of both G-II and B-II was less than that obtained from TGA data. The inconsistency is due to (i) the propensity of the LDHs to exchange their intercalated water with the ambient humidity, and (ii) the incidence of stacking disorders, which distort the XRPD profile.

(2) The full-profile simulation of the XRPD patterns was not realized as only the metal hydroxide layers were used in all the DIFFaX simulations. The determination of the positions of the intercalated atoms in a faulted structure is beyond the scope of this work.

\section{CONCLUSIONS}

Lithium sulfate imbibition into both bayerite and gibbsite led to the formation of poorly ordered $\mathrm{SO}_{4}{ }^{2-}$-intercalated LDHs. Partial dehydration resulted in ordered structures. The gibbsitederived phase had a structure different from that of the bayeritederived phase. Structure refinement provided structure models, which showed that the sulfate ions form hydrogen bonds with the intercalated water molecules as well as with the hydroxyl ions. Increased humidity caused the ingress of water molecules from the ambient environment into the interlayer region, and resulted in a reversible expansion of the basal spacing. Expansion of the 
basal spacing provides the crystal-chemical basis for the swelling of the LDH, and its clay-like character.

\section{ACKNOWLEDGMENTS}

The authors are grateful to the Department of Science and Technology (DST), Government of India, for financial support. L.P. is a recipient of support under the Women Scientists (WOS-A) Scheme of the DST.

\section{REFERENCES}

Besserguenev, A. V., Fogg, A.M., Francis, R.J., Price, S.J., O’Hare, D., Isupov, V.P., \& Tolochko, B.P. (1997) Synthesis and structure of the gibbsite intercalation compounds $\left[\mathrm{LiAl}_{2}(\mathrm{OH})_{6}\right] \mathrm{X}\left\{\mathrm{X}=\mathrm{Cl}, \mathrm{Br}, \mathrm{NO}_{3}\right\}$ and $\left[\mathrm{LiAl}_{2}(\mathrm{OH})_{6}\right] \mathrm{Cl} \cdot \mathrm{H}_{2} \mathrm{O}$ using synchrotron $\mathrm{X}$-ray and neutron powder diffraction. Chemistry of Materials, 9, 241-247.

Britto, S. \& Kamath, P.V. (2009) Structure of bayerite-based lithium aluminum layered double hydroxides (LDHs): Observation of monoclinic symmetry. Inorganic Chemistry, 48, 11646-11654.

Britto, S. \& Kamath, P.V. (2011) Polytypism in the lithium - aluminum layered double hydroxides : The $\left[\mathrm{LiAl}_{2}(\mathrm{OH})_{6}\right]^{+}$layer as a structural synthon. Inorganic Chemistry, 50, 5619-5627.

Britto, S. \& Kamath, P.V. (2012) Structural synthon approach to the study of stacking faults in the layered double hydroxides of lithium and aluminum. Zeitschrift fur Anorganische und Allgemeine Chemie, 638, 362-365.

Britto, S., Thomas, G.S., Kamath, P.V., \& Kannan, S. (2008) Polymorphism and structural disorder in the carbonate containing layered double hydroxide of Li with Al. Journal of Physical Chemistry C, 112, 9510-9515.

Cavani, F., Trifirò, F., \& Vaccari, A. (1991) Hydrotalcite-type anionic clays: Preparation, properties and applications. Catalysis Today, 11, 173-301.

Chen, M., Zhu, R., Lu, X., Zhu, J., \& He, H. (2018) Influences of cation ratio, anion type, and water content on polytypism of layered double hydroxides. Inorganic Chemistry, 57, 7299-7313.

Fawell, J.K., Ohanian, E., Giddings, M., Toft, P., Magara, Y., \& Jackson, P. (2004). Sulfate in drinking-water Background document for development of WHO Guidelines for drinking-water quality. World Health Organization, 8.

Fogg, A.M., Green, V.M., Harvey, H.G., \& O’Hare, D. (1999) New separation science using shape-selective ion exchange intercalation chemistry. Advanced Materials, 11, 1466-1469.

Fogg, A.M., Freij, A.J., \& Parkinson, G.M. (2002) Synthesis and anion exchange chemistry of rhombohedral Li/Al layered double hydroxides. Chemistry of Materials, 14, 232-234.

Larson, A.C. \& Von Dreele, R.B. (2004). General Structure Analysis System (GSAS). Los Alamos National Laboratory Report LAUR, 748, 86-748.

Łasocha, W. \& Lewinski, K. (1994) PROSZKI - a system of programs for powder diffraction data analysis. Journal of Applied Crystallography, 27, 437-438.

Megaw, H.D. (1934) The crystal structure of hydrargillite, $\mathrm{Al}(\mathrm{OH})$. Zeitschrift für Kristallographie - Crystalline Materials, 87, 185205.

Moosa, S., Nemati, M., \& Harrison, S.T.L. (2005) A kinetic study on anaerobic reduction of sulphate, part II: Incorporation of temperature effects in the kinetic model. Chemical Engineering Science, 60, 3517-3524.

Nagendran, S. \& Kamath, P.V. (2013) Structure of the chloride- and bromide-intercalated layered double hydroxides of $\mathrm{Li}$ and $\mathrm{Al}$ -
Interplay of coulombic and hydrogen-bonding interactions in the interlayer gallery. European Journal of Inorganic Chemistry, 2013, 4686-4693.

Nagendran, S. \& Kamath, P.V. (2017) Synthon approach to structure models for the bayerite-derived layered double hydroxides of $\mathrm{Li}$ and Al. Inorganic Chemistry, 56, 5026-5033.

Nagendran, S., Periyasamy, G., \& Kamath, P.V. (2016) Structure models for the hydrated and dehydrated nitrate-intercalated layered double hydroxide of Li. Dalton Transactions, 45, 18324-18332.

Nagendran, S., Periyasamy, G., \& Kamath, P.V. (2018) Hydrationinduced interpolytype transformations in the bayerite-derived nitrate-intercalated layered double hydroxide of $\mathrm{Li}$ and Al. Journal of Solid State Chemistry, 266, 226-232.

Poeppelmeier, K.R. \& Hwu, S.J. (1987) Synthesis of lithium dialuminate by salt imbibition. Inorganic Chemistry, 26, 32973302.

Pol, L.W.H., Lens, P.N.L., Stams, A.J.M., \& Lettinga, G. (1998) Anaerobic treatment of sulphate-rich wastewaters. Biodegradation, 9, 213-224.

Prasanna, S. V. \& Kamath, P.V. (2008) Chromate uptake characteristics of the pristine layered double hydroxides of $\mathrm{Mg}$ with Al. Solid State Sciences, 10, 260-266.

Prasanna, S. V., Rao, R.A.P., \& Kamath, P.V. (2006) Layered double hydroxides as potential chromate scavengers. Journal of Colloid and Interface Science, 304, 292-299.

Rhee, S.W., Kang, M.J., Kim, H., \& Moon, C.H. (1997) Removal of aquatic chromate ion involving rehydration reaction of calcined layered double hydroxide $\left(\mathrm{Mg}-\mathrm{Al}-\mathrm{CO}_{3}\right)$. Environmental Technology, 18, 231-236.

Rothbauer, R., Zlgan, F., \& O'daniel, H. (1967) Refinement of the structure of the bayerite, $\mathrm{Al}(\mathrm{OH})_{3}$ including a proposal for the $\mathrm{h}$ position. Zeitschrift fur Kristallographie - New Crystal Structures, 125, 317-331.

Saalfeld, H. \& Wedde, M. (1974) Refinement of the crystal structure of gibbsite, $\mathrm{Al}(\mathrm{OH})_{3}$. Zeitschrift fur Kristallographie, 139, 120-135.

Serna, C.J., Rendon, J.L., \& Iglesias, J.E. (1982) Crystal-chemical study of layered $\left[\mathrm{A}_{2}{ }_{2} \mathrm{Li}(\mathrm{OH})_{6}\right]^{+} \mathrm{X}^{-1} \mathrm{n} \mathrm{H}_{2} \mathrm{O}$. Clays and Clay Minerals, 30, 180-184.

Smith, D.W. (1977) Ionic hydration enthalpies. Journal of Chemical Education, 54, 540.

Soediono, B. (1989) General structure analysis system. Journal of Chemical Information and Modeling, 53, 160.

Thiel, J.P., Chiang, C.K., \& Poeppelmeier, K.R. (1993) Structure of $\mathrm{LiAl}_{2}(\mathrm{OH})_{7} \cdot 2 \mathrm{H}_{2} \mathrm{O}$. Chemistry of Materials, 12, 297-304.

Treacy, M.M.J., Newsam, J.M., \& Deem, M.W. (1991). A general recursion method for calculating diffracted intensities from crystals containing planar faults. Proceedings of the Royal Society A: Mathematical, Physical and Engineering Sciences.

Treacy, M.M.J., Deem, M.W., \& Newsam, J.M. (2005). DIFFaX version 1.812; http://www.public.asu.edu/ mtreacy/DIFFaX.html. $1-71 \mathrm{pp}$.

Warren, B.E. \& Bodenstein, P. (1966) The shape of two-dimensional carbon black reflections. Acta Crystallographica, 20, 602-605.

Yang, L., Shahrivari, Z., Liu, P.K.T., Sahimi, M., \& Tsotsis, T.T. (2005) Removal of trace levels of arsenic and selenium from aqueous solutions by calcined and uncalcined layered double hydroxides (LDH). Industrial and Engineering Chemistry Research, 44, 6804-6815.

You, Y.W., Zhao, H.T., \& Vance, G.F. (2001) Environmental technology removal of arsenite from aqueous solutions by anionic clays. Environmental Technology, 2212, 37-41.

[Received 10 September 2018; revised 4 December 2018; AE: Runliang Zhu] 